\title{
NUCLEOTIDE DIVERSITY OF 15 CONIFER SPECIES IN VIETNAM' S CENTRAL HIGHLAND BASED ON THE ANALYSIS OF ITS, trnH-psbA, matK, trnL AND rpoC1 GENE REGIONS
}

\author{
Dinh Thi Phong ${ }^{1,2, *}$, Vu Thi Thu Hien ${ }^{1}$, Tran Thi Lieu ${ }^{1}$ \\ ${ }^{1}$ Vietnam National Museum of Nature, VAST, 18 Hoang Quoc Viet, Cau Giay, Hanoi \\ ${ }^{2}$ Graduate University of Science and Technology, VAST, 18 Hoang Quoc Viet, Cau Giay, Ha Noi \\ "Email: dinhthiphong@hotmail.com
}

Received: 26 April 2017; Accepted for publication: 30 November 2017

\begin{abstract}
In this study, five DNA sequences from ITS, trn $\mathrm{H}-p s b \mathrm{~A}$, mat $\mathrm{K}, t r n \mathrm{~L}$ and $r p o \mathrm{C} 1$ gene regions were used to explore relationships of 15 conifer species in Highland of Vietnam. All target gene segments have been cloned at size as predicted by the theory for all 15 species of conifers. Nucleotide-level change of 15 coniferous species in five gene regions showed from the highest to the lowest as follows: the ITS gene region (0.428), the trnH-psbA region (0.378), the $\operatorname{trn} \mathrm{L}(0.354)$, the matK gene $(0.192)$ and the $r p o \mathrm{C} 1$ gene $(0.105)$. The matK gene region showed the highest level of conservation (671 nucleotides) and the $t r n \mathrm{H}-p s b \mathrm{~A}$ gene region showed the lowest (78 nucleotides). Phylogenetic tree showed that the species in the same family are formatted in a separate evolutionary branch with bootstrap values obtained from the branching nodes of each species ranging from 52 to $97 \%$ for the ITS gene, from 50 to $100 \%$ for $t r n \mathrm{H}$ $p s b \mathrm{~A}$ gene region, from 66 to $100 \%$ for matK gene region, from 50 to $100 \%$ for $\operatorname{trn} \mathrm{L}$ gene region and from 57 to $100 \%$ for $r p o \mathrm{C} 1$ gene region. Of the three gene regions of $m a t \mathrm{~K}, t r n \mathrm{~L}$ and $r p o \mathrm{C} 1$, the grouping of species in the same family showed the most obvious. This result suggests the three gene regions of mat $\mathrm{K}, \operatorname{trn} \mathrm{L}$ and $r p o \mathrm{C} 1$ could be used as barcode for the 15 conifer species in Central Highland of Vietnam.
\end{abstract}

Keywords: conifer, gene regions, Highland, taxonomic classification.

Classification numbers: 1.3.2; 3.1.2.

\section{INTRODUCTION}

Viet Nam is considered one of ten 'hot spot' for pine conservation in the world, with more than half of its 34 species includes in the Red Book of Global endangered species. Central Highland is regarded as the cradle of coniferous species of Viet Nam. There are 15 species of conifers found in this area [1], of which six conifer species have been recently evaluated as globally threatened. They are: Pinus krempfii (VU B1+2c), Pinus dalatensis (VU B1+2c), Pinus latteri (NT), Fokienia hodginsii (NT), Calocedrus macrolepis (VU B1 + 2b), and Cephalotaxus mannii (VU A1d) [2]. 
DNA sequences are considered suitable for taxonomic classification by different levels of nucleotide to maintain the conservation in taxa. Today, DNA barcoding is considered an effective technique for distinguishing species. Herbert et al. [3] developed this technique into a tool of classification using short DNA sequence fragments, the nucleotide sequences of the mitochondrial genome in animals and sequences of the chloroplast genome in plants. DNA barcoding has been applied very successfully in the animal taxa. However, despite the fact that it has become an effective tool for plant classification in many studies [4, 5], DNA barcoding application in plants is still controversial $[6,7]$. One of the biggest challenges for plant barcoding is distinguishing the sister species in the same geography. The main concern is that genetic barcoding-based system may not be able to distinguish them if the nucleotide variety is too small. Therefore, researchers have focused on specific DNA regions to classify plant species. Of the gene regions, $r b c \mathrm{~L}$ and $m a t \mathrm{~K}$ are being widely used as the "DNA barcode" for plants [8, 9]. In this study, we present results on nucleotide diversity of 15 conifer species in Vietnam's Central Highland based on the analysis of ITS, $t r n \mathrm{H}-p s b \mathrm{~A}, m a t \mathrm{~K}, \operatorname{trn} \mathrm{L}$ and $r p o \mathrm{C} 1$ gene regions, aiming to further extend the scientific basis for molecular analysis-based research. The results of this study provide data of the gene regions which can be used to identify not only some conifer species of high values in the Central Highland of Vietnam, but also some species that have been challenging for field botanists to morphologically classify.

\section{MATERIALS AND METHODS}

\subsection{Materials}

In this study, the inner barks from 29 to 38 mature trees (> $20 \mathrm{~cm} \mathrm{dbh)} \mathrm{were} \mathrm{randomly}$ sampled from 45 sites, representing the natural range of 15 species (three sites for each species, depending on their distribution in Kon Tum, Lam Dong, Dak Lak and Gia Lai provinces, Figure 1 and Table 1). The nucleotide sequences and the theoretical size of the five primer pairs used in the study is shown in Table 2. Total genomic DNA was isolated from leaves using the method described by Doyle and Doyle [10].

\subsection{Methods}

MEGA v. 4.0.2 [11] was also used to calculate the proportion of sites differing between pairs of sequences. These are quoted in the text as percentage differences. In the phylogenetic inference method, gaps were not considered as character states. The phylogenetic trees were reconstructed using Neighbor joining method and bootstrap test of phylogeny with 1000 replications [12]. The sequence distances were calculated using nucleotide substitution model: Maximum Composite Likelihood [11]. The gaps and missing data were deleted. Substitutions include the transition and transversions. Pattern among lineages was homogeneous and rates among sites were uniform. 
Table 1. Samples' codes, genotypes' locations and conservation status of the fifteen coniferous species.

\begin{tabular}{|c|c|c|c|c|c|c|c|}
\hline No. & $\begin{array}{l}\text { Name of } \\
\text { family }\end{array}$ & $\begin{array}{c}\text { Name of } \\
\text { species and } \\
\text { conservation } \\
\text { status } \\
\text { (IUCN 2013) }\end{array}$ & $\begin{array}{l}\text { Collection } \\
\text { locality }\end{array}$ & Sample code & $\begin{array}{l}\text { Altitude } \\
\quad(\circ \mathbf{N})\end{array}$ & $\begin{array}{l}\text { Longitude } \\
\quad(\circ \mathbf{E})\end{array}$ & $\begin{array}{l}\text { Elevation } \\
\quad(\mathbf{m})\end{array}$ \\
\hline \multirow[t]{3}{*}{1} & \multirow[t]{3}{*}{ Cephalotaxaceae } & \multirow{3}{*}{$\begin{array}{l}\text { Cephalotaxus } \\
\text { mannii Hook.f. } \\
-\quad \text { VU A4acd, } \\
\text { B1, 2ab, C }\end{array}$} & $\begin{array}{l}\text { Ta Nung, Da Lat, } \\
\text { Lam Đong }\end{array}$ & VNMN000325 & $11^{\circ} 56^{\prime} 01.3^{\prime \prime}$ & $108^{\circ} 23^{\prime} 12.5^{\prime \prime}$ & 1364 \\
\hline & & & $\begin{array}{l}\text { Hiep An, Duc } \\
\text { Trong, Lam Dong }\end{array}$ & VNMN000330 & $11^{\circ} 50^{\prime} 13.3^{\prime \prime}$ & $108^{\circ} 25^{\prime} 37.5^{\prime \prime}$ & 1392 \\
\hline & & & $\begin{array}{l}\text { Hiep An, Duc } \\
\text { Trong, Lam Dong }\end{array}$ & VNMN000336 & $11^{\circ} 50^{\prime} 13.3^{\prime \prime}$ & $108^{\circ} 25^{\prime} 37.5^{\prime \prime}$ & 1392 \\
\hline \multirow[t]{3}{*}{2} & \multirow[t]{9}{*}{ Cupressaceae } & \multirow{3}{*}{$\begin{array}{l}\text { Fokienia } \\
\text { hodginsii A. } \\
\text { Henry \& H.H. } \\
\text { Thomas } \\
\text { - EN A4acd } \\
\text { B2ab(iii,v) }\end{array}$} & $\begin{array}{ll}\text { Da Chais, } & \text { Lac } \\
\text { Duong, } & \text { Lam } \\
\text { Dong } & \end{array}$ & VNMN000359 & $12^{\circ} 11^{\prime} 02.7^{\prime \prime}$ & $108^{\circ} 41^{\prime} 24.3^{\prime \prime}$ & $1400-1500$ \\
\hline & & & $\begin{array}{ll}\text { Da Chais, } & \text { Lac } \\
\text { Duong, } & \text { Lam } \\
\text { Dong } & \\
\end{array}$ & VNMN000362 & $12^{\circ} 03^{\prime} 43.8^{\prime \prime}$ & $108^{\circ} 37^{\prime} 93^{\prime \prime}$ & $1400-1500$ \\
\hline & & & $\begin{array}{ll}\text { Da Chais, } & \text { Lac } \\
\text { Duong, } & \text { Lam } \\
\text { Dong } & \\
\end{array}$ & VNMN000363 & $12^{\circ} 08^{\prime} 11.2^{\prime \prime}$ & $108^{\circ} 38^{\prime} 44.9^{\prime \prime}$ & $1400-1500$ \\
\hline \multirow[t]{3}{*}{3} & & \multirow{3}{*}{ 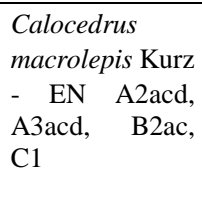 } & $\begin{array}{l}\text { Datanla, Da Lat, } \\
\text { Lam Dong }\end{array}$ & VNMN000364 & $11^{\circ} 54^{\prime} 02.5^{\prime \prime}$ & $108^{\circ} 26^{\prime} 56.8^{\prime \prime}$ & 1315 \\
\hline & & & $\begin{array}{l}\text { Hoa Son, Krong } \\
\text { Bong, Dak Lak }\end{array}$ & VNMN000396 & $12^{\circ} 25^{\prime} 05.0^{\prime \prime}$ & $108^{\circ} 22^{\prime} 17.0^{\prime \prime}$ & 1200 \\
\hline & & & $\begin{array}{l}\text { Son Lang, K' } \\
\text { Bang, Gia Lai }\end{array}$ & VNMN000430 & $14^{\circ} 30^{\prime} 52.0^{\prime \prime}$ & $108^{\circ} 33^{\prime} 21.0^{\prime \prime}$ & $1040-1057$ \\
\hline \multirow[t]{3}{*}{4} & & \multirow{3}{*}{ 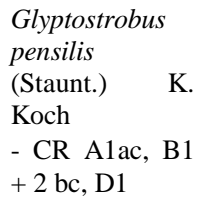 } & $\begin{array}{l}\text { Eaho, Krong } \\
\text { Nang, Dak Lak }\end{array}$ & VNMN000434 & $12^{\circ} 59^{\prime} 08.0^{\prime \prime}$ & $108^{\circ} 17^{\prime} 01.0^{\prime \prime}$ & 712 \\
\hline & & & $\begin{array}{lr}\text { Eaho, Krong } \\
\text { Nang, Dak Lak } \\
\end{array}$ & VNMN000436 & $12^{\circ} 59^{\prime} 07.0^{\prime \prime}$ & $108^{\circ} 17^{\prime} 03.0^{\prime \prime}$ & 712 \\
\hline & & & $\begin{array}{lr}\text { Eaho, Krong } \\
\text { Nang, Dak Lak }\end{array}$ & VNMN000438 & $12^{\circ} 60^{\prime} 01.0^{\prime \prime}$ & $108^{\circ} 18^{\prime} 06.0^{\prime \prime}$ & 712 \\
\hline \multirow[t]{3}{*}{5} & \multirow[t]{11}{*}{ Pinaceae } & \multirow{3}{*}{$\begin{array}{l}\text { Keteleria } \\
\text { evelyniana } \\
\text { Mast. } \\
\text { VU A4acd, } \\
\text { B1+2b(ii,iii,v), } \\
\text { C }\end{array}$} & $\begin{array}{l}\text { Suoi Vang, Da } \\
\text { Lat, Lam Dong }\end{array}$ & VNMN000439 & $11^{\circ} 59^{\prime} 58.8^{\prime \prime}$ & $108^{\circ} 21^{\prime} 59.3 ”$ & 1464 \\
\hline & & & $\begin{array}{l}\text { Hoa Son, Krong } \\
\text { Bong, Dak Lak }\end{array}$ & VNMN000465 & $12^{\circ} 25^{\prime} 05.2^{\prime \prime}$ & $108^{\circ} 22^{\prime} 17.1^{\prime \prime}$ & 1116 \\
\hline & & & $\begin{array}{l}\text { Dak Glei, Dak } \\
\text { Glei, Kon Tum }\end{array}$ & VNMN000470 & $15^{\circ} 01^{\prime} 17.0^{\prime \prime}$ & $107^{\circ} 48^{\prime} 04.0^{\prime \prime}$ & 1553 \\
\hline \multirow[t]{3}{*}{6} & & \multirow{3}{*}{$\begin{array}{l}\text { Pinus dalatensis } \\
\text { Ferré } \\
-\quad \text { VU A2acd, } \\
\text { A3acd, B2ac, } \\
\text { C1 }\end{array}$} & $\begin{array}{ll}\text { Da Chais, } & \text { Lac } \\
\text { Duong, } & \text { Lam } \\
\text { Dong } & \\
\end{array}$ & VNMN000500 & $12^{\circ} 11^{\prime} 02.7^{\prime \prime}$ & $108^{\circ} 41^{\prime} 24.3^{\prime \prime}$ & 1482 \\
\hline & & & $\begin{array}{l}\text { Hoa Son, Krong } \\
\text { Bong, Dak Lak }\end{array}$ & VNMN000529 & $12^{\circ} 29^{\prime} 33.2^{\prime \prime}$ & $108^{\circ} 18^{\prime} 17.1^{\prime \prime}$ & 1116 \\
\hline & & & $\begin{array}{l}\text { Xa Hieu, Kon } \\
\text { Plong, Kon Tum }\end{array}$ & VNMN000564 & $14^{\circ} 40^{\prime} 40.0^{\prime \prime}$ & $108^{\circ} 23^{\prime} 36.0^{\prime \prime}$ & 1159 \\
\hline \multirow[t]{3}{*}{7} & & \multirow{3}{*}{$\begin{array}{lr}\text { Pinus } & \text { kesiya } \\
\text { Royle } & \text { ex } \\
\text { Gordon } & \\
\text { (VU A4 } & \text { acd, } \\
\text { B2ac, C1) } & \end{array}$} & $\begin{array}{l}\text { Suoi Vang, Da } \\
\text { Lat, Lam Dong }\end{array}$ & VNMN000579 & $11^{\circ} 59^{\prime} 58.8^{\prime \prime}$ & $108^{\circ} 21^{\prime} 59.3 "$ & 1464 \\
\hline & & & $\begin{array}{ll}\text { Da Chais, } & \text { Lac } \\
\text { Duong, } & \text { Lam } \\
\text { Dong } & \\
\end{array}$ & VNMN000584 & $12^{\circ} 11^{\prime} 02.7^{\prime \prime}$ & $108^{\circ} 41^{\prime} 24.3 ”$ & 1482 \\
\hline & & & $\begin{array}{ll}\text { Da Chais, } & \text { Lac } \\
\text { Duong, } & \text { Lam } \\
\text { Dong } & \\
\end{array}$ & VNMN000585 & $12^{\circ} 08^{\prime} 11.2^{\prime \prime}$ & $108^{\circ} 38^{\prime} 44.9^{\prime \prime}$ & $1400-1500$ \\
\hline \multirow[t]{2}{*}{8} & & \multirow{2}{*}{$\begin{array}{ll}\text { Pinus } & \text { latteri } \\
\text { Mason } & \\
\text { (VU) } & \end{array}$} & $\begin{array}{l}\text { Hiệp An, Duc } \\
\text { Trong, Lam Dong }\end{array}$ & VNMN000586 & $11^{\circ} 49^{\prime} 52.5^{\prime \prime}$ & $108^{\circ} 25^{\prime} 26.0^{\prime \prime}$ & 1390 \\
\hline & & & $\begin{array}{l}\text { Hiệp An, Duc } \\
\text { Trong, Lam Dong }\end{array}$ & VNMN000589 & $11^{\circ} 50^{\prime} 36.1 "$ & $108^{\circ} 28^{\prime} 21.5^{\prime \prime}$ & 1390 \\
\hline
\end{tabular}




\begin{tabular}{|c|c|c|c|c|c|c|c|}
\hline & & & $\begin{array}{l}\text { Dak Glei, Dak } \\
\text { Glei, Kon Tum }\end{array}$ & VNMN000591 & $15^{\circ} 01^{\prime} 17.0$ ', & $107^{\circ} 48^{\prime} 04.0^{\prime \prime}$ & 1553 \\
\hline \multirow[t]{3}{*}{9} & & \multirow{3}{*}{$\begin{array}{l}\text { Pinus krempfii } \\
\text { Lecomte } \\
\text { (VU A2acd, } \\
\text { A3acd, B2ac, } \\
\text { C1) }\end{array}$} & $\begin{array}{lr}\text { Da Chais, } & \text { Lac } \\
\text { Dương, } & \text { Lam } \\
\text { Dong } & \end{array}$ & VNMN000592 & $12^{\circ} 11^{\prime} 01.3^{\prime \prime}$ & $108^{\circ} 41^{\prime} 20.3 ”$ & $\begin{array}{l}1482 \\
1485\end{array}$ \\
\hline & & & $\begin{array}{l}\text { Lat, Lac Dương, } \\
\text { Lam Dong }\end{array}$ & VNMN000606 & $12^{\circ} 05^{\prime} 17.9^{\prime \prime}$ & $108^{\circ} 22^{\prime} 13.0^{\prime \prime}$ & $1659-1757$ \\
\hline & & & $\begin{array}{l}\text { Hoa Son, Krong } \\
\text { Bong, Dak Lak }\end{array}$ & VNMN000642 & $12^{\circ} 25^{\prime} 05.2^{\prime \prime}$ & $108^{\circ} 22^{\prime} 17.1^{\prime \prime}$ & 1110- 1120 \\
\hline \multirow[t]{3}{*}{10} & \multirow[t]{12}{*}{ Podocarpaceae } & \multirow{3}{*}{$\begin{array}{l}\text { Dacrycarpus } \\
\text { imbricatus } \\
\text { (Blume) de } \\
\text { Laub. } \\
\text { (LC) }\end{array}$} & $\begin{array}{l}\text { Da Chais, Lac } \\
\text { Duong, } \\
\text { Dong }\end{array}$ & VNMN000662 & $12^{\circ} 11^{\prime} 02.5^{\prime \prime}$ & $108^{\circ} 41^{\prime} 24.0^{\prime \prime}$ & 1482 \\
\hline & & & $\begin{array}{l}\text { Da Chais, Lac } \\
\text { Duong, } \\
\text { Dong }\end{array}$ & VNMN000665 & $12^{\circ} 11^{\prime} 02.3^{\prime \prime}$ & $108^{\circ} 41^{\prime} 24.1 ”$ & 1482 \\
\hline & & & $\begin{array}{l}\text { Ngoc Linh, Dak } \\
\text { Glei, Kon Tum }\end{array}$ & VNMN000669 & $15^{\circ} 04^{\prime} 23.0^{\prime \prime}$ & $107^{\circ} 57^{\prime} 31.0^{\prime \prime}$ & 1935 \\
\hline \multirow[t]{3}{*}{11} & & \multirow{3}{*}{ 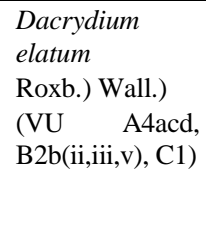 } & $\begin{array}{l}\text { Da Chais, Lac } \\
\text { Duong, } \\
\text { Dong }\end{array}$ & VNMN000670 & $12^{\circ} 11^{\prime} 02.7^{\prime \prime}$ & $108^{\circ} 41^{\prime} 24.3^{\prime \prime}$ & 1482 \\
\hline & & & $\begin{array}{l}\text { Hoa Son, Krong } \\
\text { Bong, Dak Lak }\end{array}$ & VNMN000693 & $12^{\circ} 25^{\prime} 05.2^{\prime \prime}$ & $108^{\circ} 22^{\prime} 17.1^{\prime \prime}$ & 1116 \\
\hline & & & $\begin{array}{l}\text { Xa Hieu, Kon } \\
\text { Plong, Kon Tum }\end{array}$ & VNMN000718 & $14^{\circ} 40^{\prime} 06.8^{\prime \prime}$ & $108^{\circ} 24^{\prime} 30.3^{\prime \prime}$ & 1194 \\
\hline \multirow[t]{3}{*}{12} & & \multirow{3}{*}{$\begin{array}{l}\text { Nageia } \\
\text { wallichiana } \\
\text { (C. Presl) } \\
\text { Kuntze } \\
\text { (VU B2ab(iii,v) }\end{array}$} & $\begin{array}{l}\text { Ta Nung, Da Lat, } \\
\text { Lam Dong }\end{array}$ & VNMN000740 & $11^{\circ} 56^{\prime} 01,3^{\prime \prime}$ & $108^{\circ} 53^{\prime} 12,5^{\prime \prime}$ & 1364 \\
\hline & & & $\begin{array}{l}\text { Hoa Son, Krong } \\
\text { Bong, Dak Lak }\end{array}$ & VNMN000775 & $12^{\circ} 25^{\prime} 05,2^{\prime \prime}$ & $108^{\circ} 22^{\prime} 17,1^{\prime \prime}$ & 1016 \\
\hline & & & $\begin{array}{l}\text { Xa Hieu, Kon } \\
\text { Plong, Kon Tum }\end{array}$ & VNMN000803 & $14^{\circ} 35^{\prime} 05.0 ”$ & $108^{\circ} 24^{\prime} 55.0^{\prime \prime}$ & 1267 \\
\hline \multirow[t]{3}{*}{13} & & \multirow{3}{*}{$\begin{array}{l}\text { Podocarpus } \\
\text { neriifolius } \\
\text { D. Don } \\
\text { (LC) }\end{array}$} & $\begin{array}{l}\text { Da Chais, Lac } \\
\text { Duong, } \\
\text { Dong }\end{array}$ & VNMN000810 & $12^{\circ} 11^{\prime} 13.1^{\prime \prime}$ & $108^{\circ} 42^{\prime} 55.3^{\prime \prime}$ & 1593 \\
\hline & & & $\begin{array}{l}\text { Hoa Son, Krong } \\
\text { Bong, Dak Lak }\end{array}$ & VNMN000812 & $12^{\circ} 29^{\prime} 28.3^{\prime \prime}$ & $108^{\circ} 18^{\prime} 38.4^{\prime \prime}$ & 1120 \\
\hline & & & $\begin{array}{l}\text { Đak Glei, Dak } \\
\text { Glei, Kon Tum }\end{array}$ & VNMN000814 & $15^{\circ} 01^{\prime} 17.0$ ', & $107^{\circ} 48^{\prime} 04.0^{\prime \prime}$ & 1553 \\
\hline \multirow[t]{3}{*}{14} & \multirow[t]{6}{*}{ Taxaceae } & \multirow{3}{*}{$\begin{array}{l}\text { Amentotaxus } \\
\text { poilanei } \\
\text { D.K. Ferguson } \\
\text { (VU D2) }\end{array}$} & $\begin{array}{l}\text { Ngoc Linh, Dak } \\
\text { Glei, Kon Tum }\end{array}$ & VNMN000815 & $15^{\circ} 03$ '20.0’, & $107^{\circ} 58^{\prime} 31.0^{\prime \prime}$ & 1935 \\
\hline & & & $\begin{array}{l}\text { Ngoc Linh, Dak } \\
\text { Glei, Kon Tum }\end{array}$ & VNMN000817 & $15^{\circ} 04^{\prime} 23.0^{\prime \prime}$ & $107^{\circ} 57^{\prime} 31.0^{\prime \prime}$ & 1935 \\
\hline & & & $\begin{array}{l}\text { Ngoc Linh, Dak } \\
\text { Glei, Kon Tum }\end{array}$ & VNMN000818 & $15^{\circ} 04^{\prime} 25.1^{\prime \prime}$ & $107^{\circ} 52^{\prime} 30.0^{\prime \prime}$ & 1935 \\
\hline \multirow[t]{3}{*}{15} & & \multirow{3}{*}{$\begin{array}{l}\text { Taxus } \\
\text { wallichiana } \\
\text { Zucc } \\
(\text { EN A4acd, } \\
\text { B1b,2, C1) }\end{array}$} & $\begin{array}{l}\text { Da Chais, Lac } \\
\text { Duong, } \\
\text { Dong }\end{array}$ & VNMN000819 & $12^{\circ} 03^{\prime} 43.8^{\prime \prime}$ & $108^{\circ} 37^{\prime} 93.0 "$ & 1533 \\
\hline & & & $\begin{array}{lr}\text { Da Chais, } & \text { Lac } \\
\text { Duong, } & \text { Lam } \\
\text { Dong } & \\
\end{array}$ & VNMN000823 & $12^{\circ} 08^{\prime} 11.2^{\prime \prime}$ & $108^{\circ} 38^{\prime} 44.9^{\prime \prime}$ & $1400-1500$ \\
\hline & & & $\begin{array}{l}\text { Da Chais, Lac } \\
\text { Duong, } \\
\text { Dong }\end{array}$ & VNMN000827 & $12^{\circ} 11^{\prime} 02.7^{\prime \prime}$ & $108^{\circ} 41^{\prime} 24.3^{\prime \prime}$ & $1400-1500$ \\
\hline
\end{tabular}




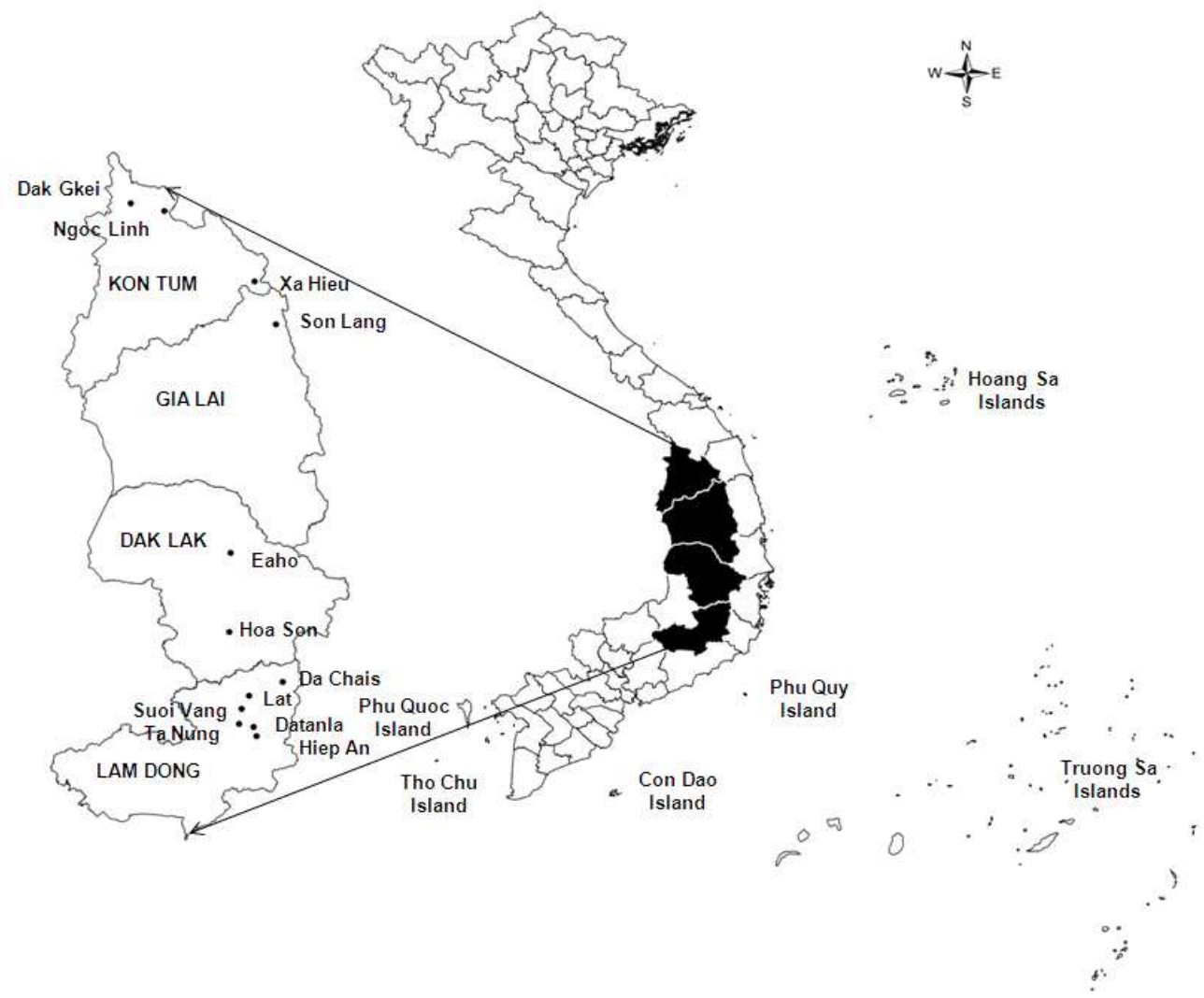

Table 2. List of primer pairs used in this study.

\begin{tabular}{|c|c|c|c|c|}
\hline $\begin{array}{l}\text { Primer } \\
\text { names }\end{array}$ & Primer sequences $\left(5^{\prime}-3^{\prime}\right)$ & $\begin{array}{l}\text { Expected } \\
\text { size (bp) }\end{array}$ & $\begin{array}{c}\text { Annealing } \\
\text { temperature } \\
\left({ }^{\circ} \mathrm{C}\right)\end{array}$ & Origin \\
\hline $\operatorname{trn} \mathrm{H} / p s b \mathrm{~A}$ & $\begin{array}{l}\text { GTTATGCATGAACGTAATGCTC } \\
\text { CGCGCATGGTGGATTCACAATCC }\end{array}$ & 680 & $50-53$ & $\begin{array}{l}\text { Sang et al., } 1997 \text { [22] } \\
\text { Tate et al., } 2003 \text { [23] }\end{array}$ \\
\hline $\begin{array}{l}\text { ITSF/ } \\
\text { ITSR }\end{array}$ & $\begin{array}{l}\text { CCTGCGGAAGGATCATTGTC } \\
\text { TTAAACTCAGCGGGTAGTC }\end{array}$ & 1100 & $50-53$ & $\begin{array}{l}\text { Designed based on Elleanthus } \\
\text { conifer coded EU490666 Genbank } \\
\text { (2014) }\end{array}$ \\
\hline $\begin{array}{l}\text { rpoC1F/ } \\
\text { rpoC1R }\end{array}$ & $\begin{array}{l}\text { GTGGATACACTTCTTGATAATGG } \\
\text { TGAGAAAACATAAGTAAACGGGC }\end{array}$ & 600 & $50-52$ & $\begin{array}{l}\text { http://www.kew.org/barcoding/pro } \\
\text { tocols.html [24] }\end{array}$ \\
\hline $\begin{array}{l}\operatorname{trn} \mathrm{LF} / \\
\operatorname{trn} \mathrm{FR}\end{array}$ & $\begin{array}{l}\text { CGAAATCGGTAGACGCTACG } \\
\text { ATTTGAACTGGTGACACGAG }\end{array}$ & 1000 & $50-53$ & Taberlet et al., 2006 [13] \\
\hline $\begin{array}{l}\text { matKF/ } \\
\text { matKR }\end{array}$ & $\begin{array}{l}\text { TGGCAFTGCAATCAAAAC } \\
\text { ATCGCTAATCAATAAATCATCT }\end{array}$ & 950 & $50-55$ & $\begin{array}{l}\text { Designed based on Taxus } \\
\text { wallichiana coded HM590991 } \\
\text { Genbank (2014) }\end{array}$ \\
\hline
\end{tabular}

\section{RESULTS AND DISCUSSIONS}

\subsection{Character analysis of gene regions}


We successfully cloned target gene fragments at sizes as theoretically predicted for all 45 samples of the 15 coniferous species. Gene fragments of three samples of the same species were amplified with the same size. Different sizes of gene segments were amplified for each species, ranging from 975 to $1200 \mathrm{bp}$ for the nuclear ITS region; from 400 to $780 \mathrm{bp}$ for the trnH-psbA region; from 650 to $1000 \mathrm{bp}$ for $m a t \mathrm{~K}$ region; from 400 to $970 \mathrm{bp}$ for the $t r n \mathrm{~L}$ region and $600 \mathrm{bp}$ for $r p o \mathrm{C} 1$ region (Figure 2). In this study, a total of 165 nucleotide sequences of the five gene regions have been obtained for fifteen species, which have been deposited in Genbank/EMBL databases, including 165 accession numbers KR780651- KR780665; KR907882- KR907890; KR920092- KR920100; KT001114- KT001125; KT150253- KT150258; KT222871KT222882; $\quad$ KT236090- $\quad$ KT236092; $\quad$ KT247644- $\quad$ KT247646; $\quad$ KT265683- $\quad$ KT265685; KT272170- KT272172; KT008100- KT008105; KT037124- KT037129; KR855700KR855711; KR674115- KR674126; KT072777- KT072785; KR605490- KR605498 and KU940072- KU940107) available online.

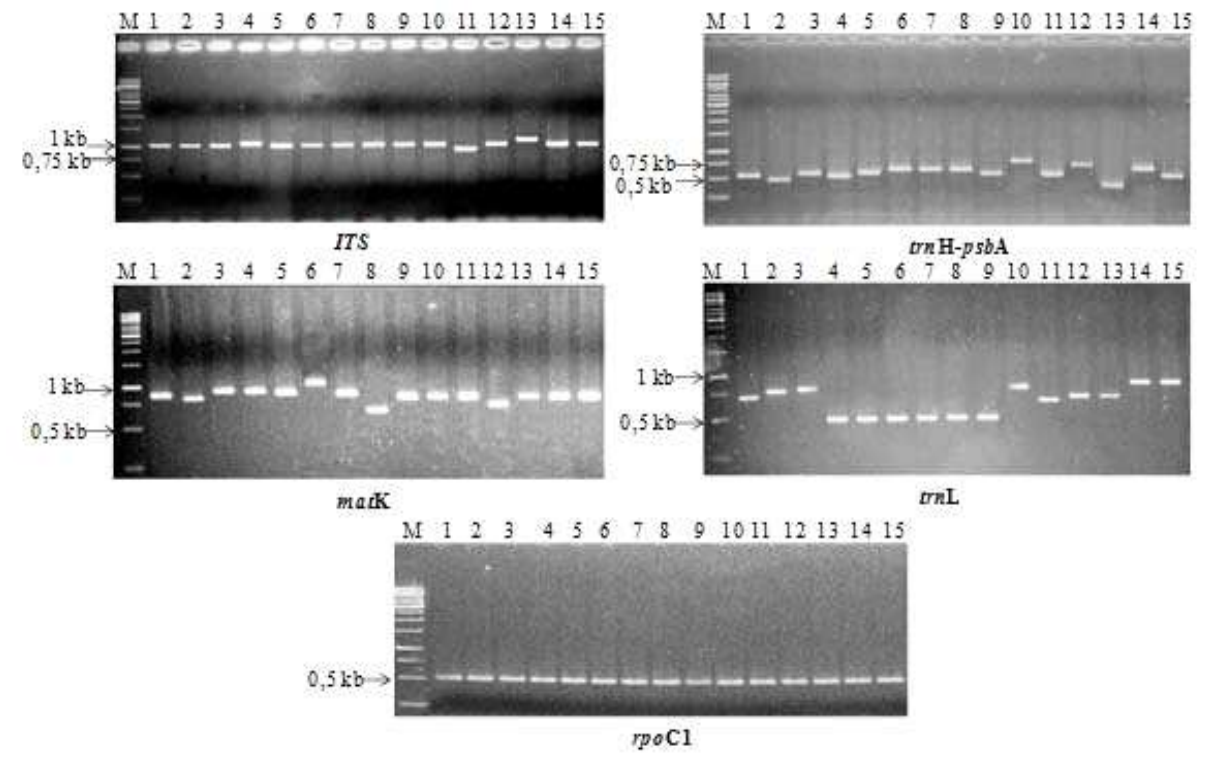

Figure 2. PCR representative products of coniferous species analyzed five gene regions on the $1 \%$ agarose (M: Molecular ladder1 kb; 1: Cephalotaxus mannii, 2: Fokienia hodginsii, 3: Calocedrus macrolepis, 4: Glytostrotrobus pensilis, 5: Keteleria evelyniana,6: Pinus dalatensis, 7: Pinus kesiya, 8: Pinus latteri, 9: Pinus krempfii, 10: Dacrycarpus imbricatus, 11: Dacrydium elatum, 12: Nageia wallichiana, 13: Podocarpus neriifolius, 14: Amentotaxus poilanei and 15: Taxus wallichiana).

\subsection{Nucleotide diversity}

Results from compared nucleotide sequences using MEGA v.4.0.2 software between samples of the same species at the ITS, $\operatorname{trn\mathrm {H}}-p s b \mathrm{~A}, \operatorname{mat\mathrm {K}}, \operatorname{tr} n \mathrm{~L}$ and $r p o \mathrm{C} 1$ gene regions showed that their length and nucleotide sequence similarity were $100 \%$. Therefore, the following study took only one representative sample of each species. The degree of nucleotide diversity among 15 species ranged from 0.000 (such as $P$. latteri with $P$. dalatensis, $P$. krempfii with $P$. dalatensis, $P$. kesiya with $P$. krempfii, etc...) to $2.642 \%$ (P. neriifolius with $C$. macrolepis) for the ITS gene (Table 3); From 0.000 (P. latteri with P. kesiya) to $3.552 \%$ ( $P$. wallichiana with $P$. kesiya and $P$. latteri) for trnH-psbA region (Table 4); from 0.009 (P. latteri with P. kesiya) to $0.367 \%$ (between $P$. neriifolius with $P$. kesiya and $P$. latteri) for the matK region (Table 5); 
From 0.000 (between $F$. hodginsii and C. macrolepis) to $1.237 \%$ (between $K$. evelyniana and $P$. dalatensis) for $\operatorname{trn} \mathrm{L}$ gene region (Table 6); from 0.000 (between $P$. dalatensis and P. krempfii) to $0.177 \%$ (between C. macrolepis with K. evelyniana, P. dalatensis, P.latteri and P. krempfii) for the $r p o \mathrm{C} 1$ region (Table 7). Among the five regions, the $t r n \mathrm{H}-p s b \mathrm{~A}$ region showed the highest level of nucleotide diversity (from 0.000 to $3.552 \%$ ) and the $r p o \mathrm{C} 1$ region showed the lowest (from 0.000 to $0.177 \%$ ).

In this study, characters of conservation, variation and parsimony information were 124 , 1146 and 801 for the nuclear ITS gene; 78, 726 and 546 for the $t r n \mathrm{H}-p s b \mathrm{~A}$ region; 671, 487 and 331 for the matK gene; 218, 778 and 493 for the $\operatorname{trn} \mathrm{L}$ gene; and 372, 190 and 127 for the rpoC1 gene. The number of variable sites (V) for individual loci among fifteen species ranged from 190 (rpoC1) to 1146 (ITS). The value of the highest conservative characters (C) across fifteen species was 671 for the mat $\mathrm{K}$ region and the lowest for $t r n \mathrm{H}-p s b \mathrm{~A}$ region (78) (Table 8). Analysis results of the five gene regions showed that among 15 species, the nuclear ITS gene had the highest level of nucleotide diversity (0.428), followed by the trnH-psbA region (0.378), the $t r n \mathrm{~L}$ gene $(0.354)$, is the mat $\mathrm{K}$ gene $(0.192)$. The $r p o \mathrm{C} 1$ gene had the lowest level $(0.105)$ (Table 8). They also showed that, the chloroplast gene regions had the more conservative characters than the nuclear ITS gene region.

We also checked the divergence to distinguish species among the 15 ones, the mat $\mathrm{K}$ is the most powerful, with $100 \%$ discriminated species pairs. Another species pairs similarity was founded in each of three gene regions: trnH-psbA (VNMN000586_ $P$. latteri and VNMN000579_ $P$. kesiya), trnL (VNMN000359_F. hodginsii and VNMN000364_C. macrolepis) and rpoC1 (VNMN000509_P. dalatensis and VNMN000592_P. krempfii) (Table 4, 6 and 7).

\subsection{Phylogeny based on gene regions}

Because samples (individuals) of the same species have the identical sequence, only one individual of each species was selected to reconstruct the phylogenetic tree from five DNA regions of 15 coniferous species. The species were separated supported by bootstrap values $>$ $50 \%$. The phylogenetic tree of 15 coniferous species based on the analysis of method NJ (Neighbor - Joining) in Figure 3 showed that all 15 species of conifers formed a separate subsidiary and joint evolution closely together with bootstrap values obtained at the branching nodes of each species ranged from 52 to $97 \%$ for the ITS gene (Figure 3A); from 50 to $100 \%$ for the $t r n \mathrm{H}-p s b \mathrm{~A}$ region (Figure 3B); from 66 to $100 \%$ for the matK gene region (Figure 3C); from 50 to $100 \%$ for the $t r n \mathrm{~L}$ gene region (Figure 3D) and from 57 to $100 \%$ for the $r p o \mathrm{C} 1$ gene region (Figure 3E). 
Table 3. Nucleotide diversity of the 15 coniferous species analyzing ITS region.

\begin{tabular}{|c|c|c|c|c|c|c|c|c|c|c|c|c|c|c|c|c|}
\hline No. & Name of samples & 1 & 2 & 3 & 4 & 5 & 6 & 7 & 8 & 9 & 10 & 11 & 12 & 13 & 14 & 15 \\
\hline 1 & VNMN000325_C. mannii & & & & & & & & & & & & & & & \\
\hline 2 & VNMN000359_F. hodginsii & 0.725 & & & & & & & & & & & & & & \\
\hline 3 & VNMN000364_C.macrolepis & 2.614 & 2.268 & & & & & & & & & & & & & \\
\hline 4 & VNMN000434_G. pensilis & 0.640 & 0.427 & 2.617 & & & & & & & & & & & & \\
\hline 5 & VNMN000439__K. evelyniana & 1.638 & 1.902 & 2.351 & 1.673 & & & & & & & & & & & \\
\hline 6 & VNMN000509_P. dalatensis & 1.647 & 1.890 & 2.336 & 1.682 & 0.001 & & & & & & & & & & \\
\hline 7 & VNMN000579_P. kesiya & 1.647 & 1.890 & 2.336 & 1.682 & 0.001 & 0.000 & & & & & & & & & \\
\hline 8 & VNMN000586_P. latteri & 1.647 & 1.890 & 2.336 & 1.682 & 0.001 & 0.000 & 0.000 & & & & & & & & \\
\hline 9 & VNMN000592_P. krempfii & 1.647 & 1.890 & 2.336 & 1.682 & 0.001 & 0.000 & 0.000 & 0.000 & & & & & & & \\
\hline 10 & VNMN000662_D. imbricatus & 1.638 & 1.902 & 2.322 & 1.673 & 0.003 & 0.004 & 0.004 & 0.004 & 0.004 & & & & & & \\
\hline 11 & VNMN000670_D. elatum & 1.699 & 1.918 & 2.447 & 1.754 & 0.011 & 0.011 & 0.011 & 0.011 & 0.011 & 0.013 & & & & & \\
\hline 12 & VNMN000740_N. wallichiana & 1.728 & 1.998 & 2.218 & 1.768 & 0.020 & 0.021 & 0.021 & 0.021 & 0.021 & 0.023 & 0.026 & & & & \\
\hline 13 & VNMN000810_P.neriifolius & 1.030 & 1.152 & 2.642 & 1.077 & 2.258 & 2.241 & 2.241 & 2.241 & 2.241 & 2.228 & 2.378 & 2.368 & & & \\
\hline 14 & VNMN000815_A.poilanei & 0.378 & 0.632 & 2.292 & 0.639 & 1.865 & 1.876 & 1.876 & 1.876 & 1.876 & 1.865 & 1.945 & 1.985 & 0.953 & & \\
\hline 15 & VNMN000819_T. wallichiana & 0.510 & 0.735 & 2.164 & 0.745 & 1.809 & 1.820 & 1.820 & 1.820 & 1.820 & 1.812 & 1.864 & 1.904 & 1.093 & 0.472 & \\
\hline
\end{tabular}


Nucleotide diversity of 15 conifer species in Viet Nam's central highland based ...

Table 4. Nucleotide diversity of the 15 coniferous species analyzing trnH-psbA region.

\begin{tabular}{|c|c|c|c|c|c|c|c|c|c|c|c|c|c|c|c|}
\hline No. & Name of samples & 1 & 2 & 3 & 4 & 5 & 6 & 7 & 8 & 9 & 10 & 11 & 12 & 13 & 14 \\
\hline 1 & VNMN000325_C. mannii & & & & & & & & & & & & & & \\
\hline 2 & VNMN000359_F. hodginsii & 0.206 & & & & & & & & & & & & & \\
\hline 3 & VNMN000364_C. macrolepis & 0.716 & 0.636 & & & & & & & & & & & & \\
\hline 4 & VNMN000434_G. pensilis & 0.441 & 0.403 & 0.134 & & & & & & & & & & & \\
\hline 5 & VNMN000439_K. evelyniana & 1.400 & 1.617 & 1.219 & 0.991 & & & & & & & & & & \\
\hline 6 & VNMN000509_P. dalatensis & 1.801 & 1.805 & 1.532 & 1.245 & 0.109 & & & & & & & & & \\
\hline 7 & VNMN000579_P. kesiya & 1.801 & 1.805 & 1.516 & 1.227 & 0.117 & 0.006 & & & & & & & & \\
\hline 8 & VNMN000586_P. latteri & 1.801 & 1.805 & 1.516 & 1.227 & 0.117 & 0.006 & 0.000 & & & & & & & \\
\hline 9 & VNMN000592_P. krempfii & 1.736 & 1.739 & 1.545 & 1.287 & 0.123 & 0.026 & 0.020 & 0.020 & & & & & & \\
\hline 10 & VNMN000662_D. imbricatus & 2.018 & 2.412 & 3.139 & 2.531 & 3.118 & 3.282 & 3.305 & 3.305 & 3.267 & & & & & \\
\hline 11 & VNMN000670_D. elatum & 1.663 & 2.056 & 2.867 & 2.361 & 3.127 & 3.247 & 3.247 & 3.247 & 3.205 & 1.540 & & & & \\
\hline 12 & VNMN000740_N. wallichiana & 2.151 & 2.424 & 3.200 & 2.680 & 3.284 & 3.529 & 3.552 & 3.552 & 3.514 & 0.089 & 1.821 & & & \\
\hline 13 & VNMN000810_P. neriifolius & 1.913 & 2.381 & 3.045 & 2.538 & 3.101 & 3.263 & 3.285 & 3.285 & 3.247 & 0.041 & 1.554 & 0.074 & & \\
\hline 14 & VNMN000815_A.poilanei & 2.243 & 2.356 & 2.388 & 1.674 & 2.450 & 2.724 & 2.743 & 2.743 & 2.633 & 2.490 & 2.740 & 2.532 & 2.656 & \\
\hline 15 & VNMN000819_T. wallichiana & 0.529 & 0.517 & 0.547 & 0.270 & 1.130 & 1.268 & 1.249 & 1.249 & 1.187 & 2.739 & 2.530 & 2.797 & 2.595 & 2.026 \\
\hline
\end{tabular}


Table 5. Nucleotide diversity of the 15 coniferous species analyzing mat $\mathrm{K}$ region.

\begin{tabular}{|c|c|c|c|c|c|c|c|c|c|c|c|c|c|c|c|}
\hline No. & Name of samples & 1 & 2 & 3 & 4 & 5 & 6 & 7 & 8 & 9 & 10 & 11 & 12 & 13 & 14 \\
\hline 1 & VNMN000325_C. mannii & & & & & & & & & & & & & & \\
\hline 2 & VNMN000359_F. hodginsii & 0.174 & & & & & & & & & & & & & \\
\hline 3 & VNMN000364_C. macrolepis & 0.167 & 0.026 & & & & & & & & & & & & \\
\hline 4 & VNMN000434_G. pensilis & 0.168 & 0.054 & 0.045 & & & & & & & & & & & \\
\hline 5 & VNMN000439_K. evelyniana & 0.232 & 0.310 & 0.288 & 0.273 & & & & & & & & & & \\
\hline 6 & VNMN000509_P.dalatensis & 0.282 & 0.344 & 0.317 & 0.314 & 0.093 & & & & & & & & & \\
\hline 7 & VNMN000579_P. kesiya & 0.287 & 0.353 & 0.331 & 0.328 & 0.093 & 0.051 & & & & & & & & \\
\hline 8 & VNMN000586_P. latteri & 0.282 & 0.348 & 0.325 & 0.322 & 0.096 & 0.061 & 0.009 & & & & & & & \\
\hline 9 & VNMN000592_P. krempfii & 0.282 & 0.348 & 0.326 & 0.319 & 0.086 & 0.039 & 0.018 & 0.020 & & & & & & \\
\hline 10 & VNMN000662__D. imbricatus & 0.254 & 0.267 & 0.256 & 0.255 & 0.290 & 0.340 & 0.348 & 0.348 & 0.339 & & & & & \\
\hline 11 & VNMN000670_D. elatum & 0.248 & 0.270 & 0.258 & 0.258 & 0.294 & 0.341 & 0.345 & 0.345 & 0.335 & 0.041 & & & & \\
\hline 12 & VNMN000740_N. wallichiana & 0.262 & 0.303 & 0.291 & 0.290 & 0.309 & 0.332 & 0.360 & 0.360 & 0.341 & 0.072 & 0.079 & & & \\
\hline 13 & VNMN000810_P. neriifolius & 0.288 & 0.316 & 0.304 & 0.297 & 0.334 & 0.346 & 0.367 & 0.367 & 0.366 & 0.079 & 0.086 & 0.060 & & \\
\hline 14 & VNMN000815_A.poilanei & 0.090 & 0.169 & 0.151 & 0.137 & 0.221 & 0.254 & 0.266 & 0.266 & 0.262 & 0.235 & 0.229 & 0.256 & 0.255 & \\
\hline 15 & VNMN000819_T. wallichiana & 0.110 & 0.159 & 0.141 & 0.131 & 0.230 & 0.264 & 0.280 & 0.275 & 0.263 & 0.238 & 0.232 & 0.247 & 0.262 & 0.054 \\
\hline
\end{tabular}


Nucleotide diversity of 15 conifer species in Viet Nam's central highland based...

Table 6. Nucleotide diversity of the 15 coniferous species analyzing $\operatorname{trn} \mathrm{L}$ region.

\begin{tabular}{|c|c|c|c|c|c|c|c|c|c|c|c|c|c|c|c|}
\hline No. & Name of samples & 1 & 2 & 3 & 4 & 5 & 6 & 7 & 8 & 9 & 10 & 11 & 12 & 13 & 14 \\
\hline 1 & VNMN000325_C. mannii & & & & & & & & & & & & & & \\
\hline 2 & VNMN000359_F. hodginsii & 0.280 & & & & & & & & & & & & & \\
\hline 3 & VNMN000364_C. macrolepis & 0.280 & 0.000 & & & & & & & & & & & & \\
\hline 4 & VNMN000434_G. pensilis & 0.297 & 0.049 & 0.049 & & & & & & & & & & & \\
\hline 5 & VNMN000439_K. evelyniana & 0.367 & 0.392 & 0.392 & 0.393 & & & & & & & & & & \\
\hline 6 & VNMN000509_P. dalatensis & 1.043 & 1.122 & 1.122 & 1.198 & 1.237 & & & & & & & & & \\
\hline 7 & VNMN000579_P. kesiya & 1.008 & 1.054 & 1.054 & 1.122 & 1.090 & 0.039 & & & & & & & & \\
\hline 8 & VNMN000586_P. latteri & 1.043 & 1.119 & 1.119 & 1.195 & 1.180 & 0.044 & 0.024 & & & & & & & \\
\hline 9 & VNMN000592_P. krempfii & 1.024 & 1.111 & 1.111 & 1.187 & 1.222 & 0.034 & 0.044 & 0.029 & & & & & & \\
\hline 10 & VNMN000662_D. imbricatus & 0.296 & 0.391 & 0.391 & 0.402 & 0.412 & 0.911 & 0.893 & 0.895 & 0.878 & & & & & \\
\hline 11 & VNMN000670_D. elatum & 0.350 & 0.488 & 0.488 & 0.502 & 0.438 & 1.089 & 1.065 & 1.086 & 1.065 & 0.101 & & & & \\
\hline 12 & VNMN000740_N. wallichiana & 0.287 & 0.379 & 0.379 & 0.390 & 0.377 & 0.913 & 0.895 & 0.911 & 0.895 & 0.039 & 0.101 & & & \\
\hline 13 & VNMN000810_P. neriifolius & 0.302 & 0.411 & 0.411 & 0.408 & 0.409 & 0.932 & 0.913 & 0.930 & 0.913 & 0.039 & 0.085 & 0.034 & & \\
\hline 14 & VNMN000815_A.poilanei & 0.172 & 0.294 & 0.294 & 0.303 & 0.359 & 1.176 & 1.116 & 1.190 & 1.182 & 0.318 & 0.339 & 0.295 & 0.294 & \\
\hline 15 & VNMN000819_T. wallichiana & 0.277 & 0.308 & 0.308 & 0.320 & 0.423 & 1.155 & 1.133 & 1.208 & 1.199 & 0.330 & 0.395 & 0.338 & 0.338 & 0.216 \\
\hline
\end{tabular}


Table 7. Nucleotide diversity of the 15 coniferous species analyzing $r p o \mathrm{C} 1$ region.

\begin{tabular}{|c|c|c|c|c|c|c|c|c|c|c|c|c|c|c|c|}
\hline No. & Name of samples & 1 & 2 & 3 & 4 & 5 & 6 & 7 & 8 & 9 & 10 & 11 & 12 & 13 & 14 \\
\hline 1 & VNMN000325_C. mannii & & & & & & & & & & & & & & \\
\hline 2 & VNMN000359_F. hodginsii & 0.082 & & & & & & & & & & & & & \\
\hline 3 & VNMN000364_C.macrolepis & 0.087 & 0.021 & & & & & & & & & & & & \\
\hline 4 & VNMN000434_G. pensilis & 0.078 & 0.047 & 0.050 & & & & & & & & & & & \\
\hline 5 & VNMN000439_K. evelyniana & 0.171 & 0.171 & 0.177 & 0.174 & & & & & & & & & & \\
\hline 6 & VNMN000509_P. dalatensis & 0.164 & 0.165 & 0.177 & 0.162 & 0.028 & & & & & & & & & \\
\hline 7 & VNMN000579_P. kesiya & 0.167 & 0.164 & 0.173 & 0.164 & 0.042 & 0.018 & & & & & & & & \\
\hline 8 & VNMN000586_P. latteri & 0.171 & 0.168 & 0.177 & 0.168 & 0.039 & 0.015 & 0.003 & & & & & & & \\
\hline 9 & VNMN000592_P. krempfii & 0.164 & 0.165 & 0.177 & 0.162 & 0.028 & 0.000 & 0.018 & 0.015 & & & & & & \\
\hline 10 & VNMN000662_D. imbricatus & 0.138 & 0.151 & 0.156 & 0.141 & 0.135 & 0.126 & 0.132 & 0.135 & 0.126 & & & & & \\
\hline 11 & VNMN000670_D. elatum & 0.151 & 0.161 & 0.166 & 0.151 & 0.142 & 0.133 & 0.139 & 0.142 & 0.133 & 0.023 & & & & \\
\hline 12 & VNMN000740_N. wallichiana & 0.144 & 0.154 & 0.160 & 0.145 & 0.139 & 0.127 & 0.133 & 0.136 & 0.127 & 0.021 & 0.034 & & & \\
\hline 13 & VNMN000810_P.neriifolius & 0.148 & 0.151 & 0.156 & 0.142 & 0.142 & 0.130 & 0.136 & 0.139 & 0.130 & 0.023 & 0.036 & 0.003 & & \\
\hline 14 & VNMN000815_A.poilanei & 0.061 & 0.081 & 0.099 & 0.078 & 0.165 & 0.152 & 0.155 & 0.158 & 0.152 & 0.123 & 0.136 & 0.130 & 0.133 & \\
\hline 15 & VNMN000819_T. wallichiana & 0.053 & 0.067 & 0.078 & 0.069 & 0.142 & 0.135 & 0.138 & 0.141 & 0.135 & 0.123 & 0.136 & 0.133 & 0.136 & 0.045 \\
\hline
\end{tabular}


Table 8. Summary of characteristics of 5 DNA barcodes evolution and ability of distinguishing species for each gene region.

\begin{tabular}{|c|c|c|c|c|c|c|}
\hline Gene regions & $\mathbf{m}$ & $\mathbf{C}$ & $\mathbf{V}$ & $\mathbf{P i}$ & $\boldsymbol{\pi}$ & $\mathbf{P \%}$ \\
\hline$I T S$ & 15 & 124 & 1146 & 801 & 0.428 & 58.2 \\
\hline trn $\mathrm{H}-p s b \mathrm{~A}$ & 15 & 78 & 726 & 546 & 0.378 & 97.1 \\
\hline matK & 15 & 671 & 487 & 331 & 0.192 & 100 \\
\hline trnL & 15 & 218 & 778 & 493 & 0.354 & 97.1 \\
\hline rpoC 1 & 15 & 372 & 190 & 127 & 0.105 & 97.1 \\
\hline
\end{tabular}

$m$ : Number of species; $C$ : Consevative characters; V: Variable characters; Pi: Parsimony informative characters; $\pi$ : nucleotide diversity. P: The power to distinguish species (\%).

The data also indicated that species in the same genus of the family clustered in the same branch of evolution. For example, five species in Pinaceae family, including Keteleeria evelyniana (VNMN000439_K. evelyniana), Pinus dalatensis (VNMN000500_P. dalatensis), Pinus kesiya (VNMN000579_P. kesiya), Pinus latteri (VNMN000586_P. latteri) and Pinus krempfii (VNMN000592_P. krempfii) formed a branch of evolution with bootstrap valuesranging from 70 to $100 \%$ for the $t r n \mathrm{H}-p s b \mathrm{~A}$ region; from 93 to $100 \%$ for the matK region, from 84 to $100 \%$ for the $t r n \mathrm{~L}$ region and from 68 to $100 \%$ for the $r p o \mathrm{C} 1$ gene region. Branching level of nuclear ITS region (Figure 3A) is the weakest in the five gene regions. The branching level was weak even between species in the same family. For example, some species in the family Pinaceae (such as VNMN000592_P. krempfii, VNMN000589_P. latteri, VNMN000500_P. dalatensis and VNMN000579_P. kesiya) formatted with the species of family Podocarpaceae (such as VNMN000662_D. imbricatus, VNMN000670_D. elatum, VNMN000740_N. wallichiana). Position classification between families on the phylogenetic tree were the most obvious in three regions of $m a t \mathrm{~K}, \operatorname{trn} \mathrm{L}$ and $r p o \mathrm{C} 1$. Principally, in the same species, they made up a branch with bootstrap values ranging from $50 \%$ (Taxaceae) for the gene region $t r n \mathrm{~L}$ (Figure 3D) to $100 \%$ (Pinaceae) with the three gene regions of matK (Figure 3C), $\operatorname{trn} \mathrm{L}$ (Figure 3D) and $r p o \mathrm{C} 1$ (Figure 3E). Therefore, the three gene regions of $m a t \mathrm{~K}, t r n \mathrm{~L}$ and rpoC1 can be used to identify 15 coniferous species in Central Highland of Viet Nam.

The five gene regions of ITS, $t r n \mathrm{~L}, m a t \mathrm{~K}, r p o \mathrm{C} 1$ and $t r n \mathrm{H}-p s b \mathrm{~A}$ were used as barcode objects in many cultivars, but they have still limitations. For example, the nuclear ITS region has not been successfully cloned for some species groups, or in the $t r n \mathrm{H}-p s b \mathrm{~A}$ gene region there are still more "indels" leading to difficulties in comparing the nucleotide sequences, or the two regions of $t r n \mathrm{~L}$ and $m a t \mathrm{~K}$ have very low nucleotide variations $[13,14]$. However, in this study, we successfully cloned the gene fragments for all of five gene regions of all 15 species. Among them, the three gene regions of $m a t \mathrm{~K}, \operatorname{trn} \mathrm{L}$ and $r p o \mathrm{C} 1$ were capable of grouping most of species in the same family together (Figure 3C, 3D and 3E). Among them, the bootstrap value of the matK region was the highest at the nodes among species of the same family (from 66 to $100 \%$ ) and among families (from 67 to $100 \%$ ), followed by the rpoC1 region (from 57 to $100 \%$ between species in the same family and from 63 to $100 \%$ between different families), and lastly is the region trnL (from 50 to $100 \%$ between species in the same family and from 51 to $79 \%$ between family together). The two nuclear gene regions of ITS and $t r n \mathrm{H}-p s b \mathrm{~A}$ did not group the species in the same family (Figure 3A and 3B). Contrast to this result, the nuclear ITS region to 
be very effective to identify the 8 Dalbergia species in the genus Dalbergia of Viet Nam [15]. However, the region $t r n \mathrm{H}-p s b \mathrm{~A}$ were proposed as DNA barcoding for species of Taxaceae [16, 17], but previous research revealed that they were not suitable for a number of Dalbergia species in the family Fabaceae in Viet Nam [13]. The matK gene region is suggested as DNA barcoding in plants [18]. In this study, this region also demonstrated its capability, which can be seen on Figure 3D. However, this gene region was not able to perform as barcode for some wood species of the genus Dalbergia of Viet Nam in the study of Phong et al. [15], while the matK gene has been unable to separate the two species $D$. entadoides and $D$. dialoides or $D$. hencei and $D$. oliveri with bootstrap value of $90 \%$ and $96 \%$, respectively. As announced by the group CBOL [19], the three gene regions of $t r n \mathrm{H}-p s b \mathrm{~A}, m a t \mathrm{~K}$ and $\operatorname{trn} \mathrm{L}$ may be appropriate for the study of DNA barcoding in plants because they are exact clones of the target gene fragments by specific primers, and decoding their sequences may make it possible to distinguish plant taxa. Meanwhile, the $t r n \mathrm{H}-p s b \mathrm{~A}$ region [17, 20] and the matK-barcode [21] have been proposed as DNA barcoding in plants. Our study reconfirmed the appropriate use of the three gene regions of $m a t \mathrm{~K}, \operatorname{trn} \mathrm{L}$ and $r p o \mathrm{C} 1$ to discriminate the 15 coniferous species in Central Highland of Viet Nam (Figure 3C, 3D and 3E). Although the efficiency of each of the gene region for these species were not similar, our results suggested that the technique of decoding and comparing different nucleotide sequences could effectively support traditional identification by morphology. Our study also proposed that the three gene regions of $m a t \mathrm{~K}, \operatorname{trn\mathrm {L}}$ and $r p o \mathrm{C} 1$ are the best option for DNA barcoding for interspecific variation of 15 coniferous species in the Central Highland of Vietnam.
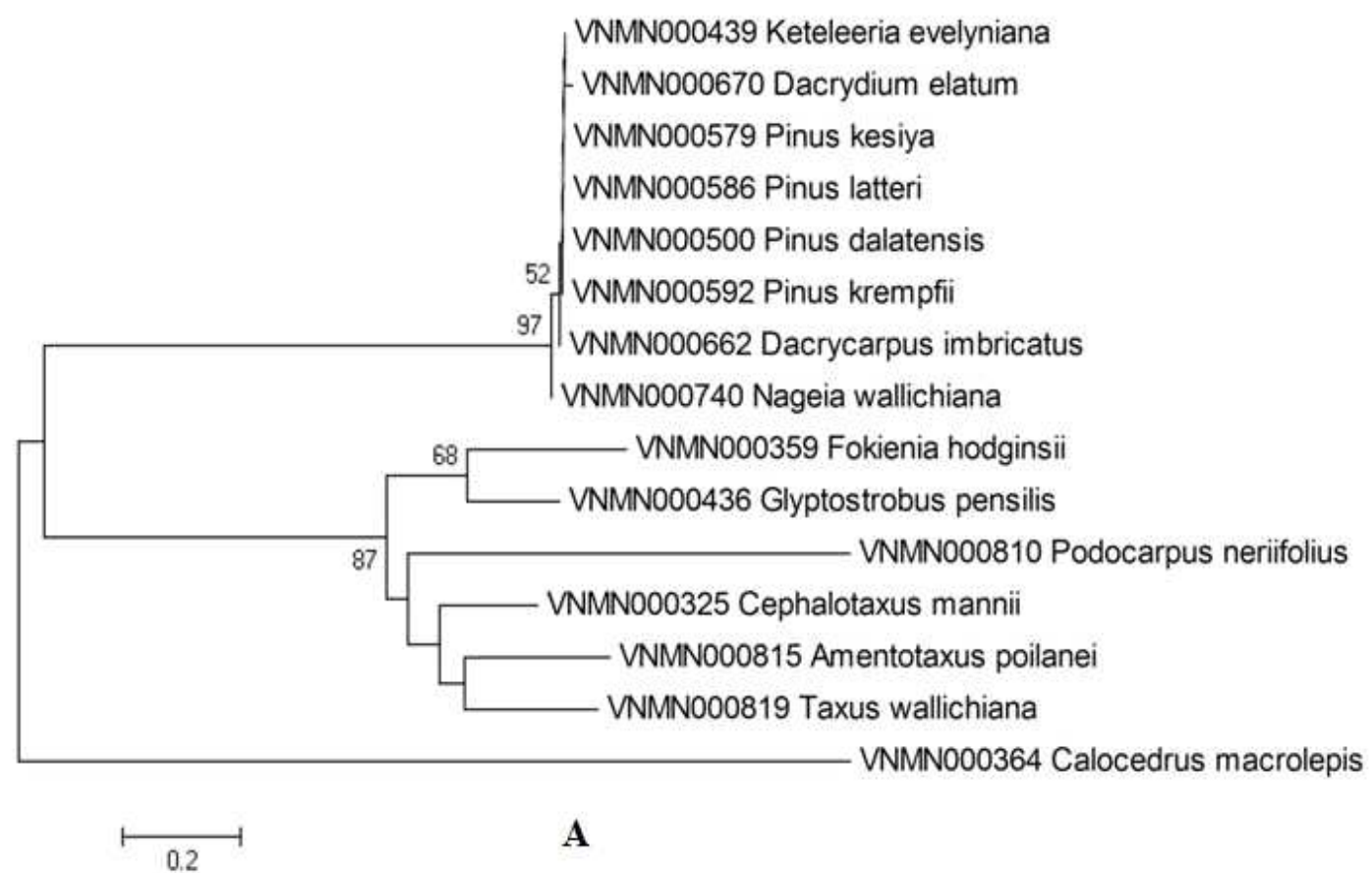

$\mathbf{A}$

Figure 3. Phylogenetic tree reconstruction using NJ method for five studied DNA regions, ITS (A), $\operatorname{trn} \mathrm{H}-$ $p s b \mathrm{~A}(\mathrm{~B}) ; m a \mathrm{~K}(\mathrm{C}) ; \operatorname{trn} \mathrm{L}(\mathrm{D})$ and $r p o \mathrm{Cl}(\mathrm{E})$. Numbers above branches indicate bootstrap values. 


\section{Nucleotide diversity of 15 conifer species in Viet Nam's central highland based}
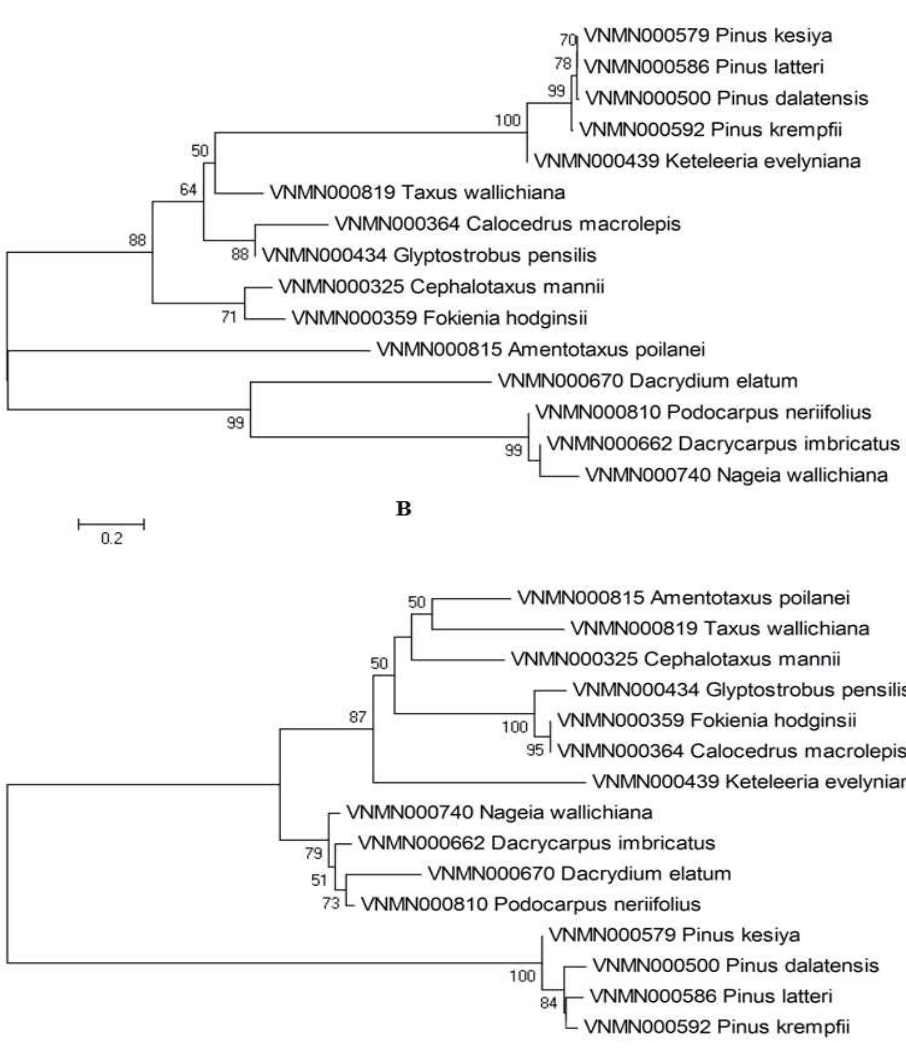

$\longmapsto .1$
Pinaceae

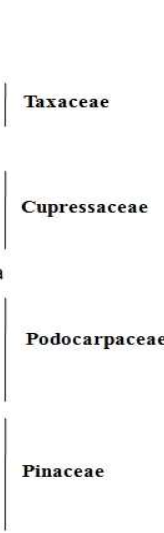

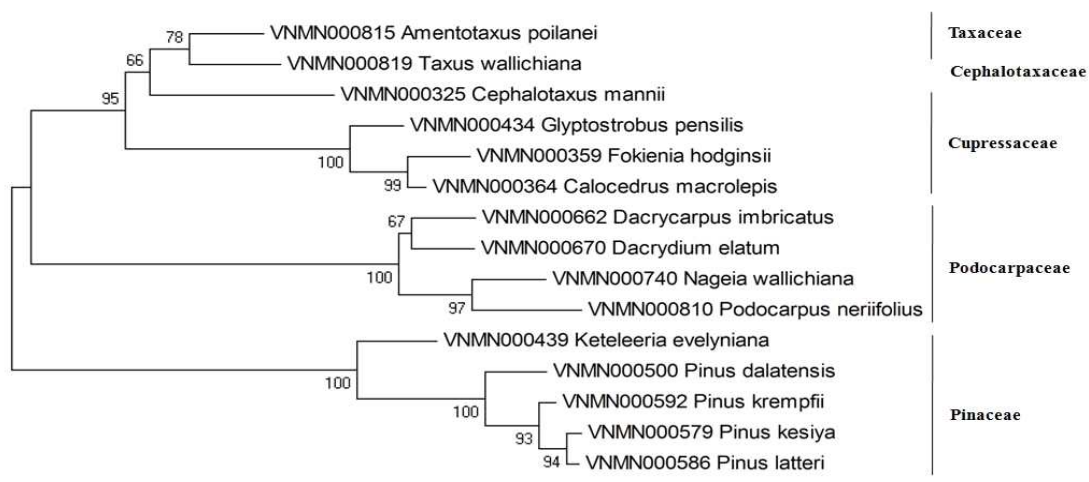

0.05

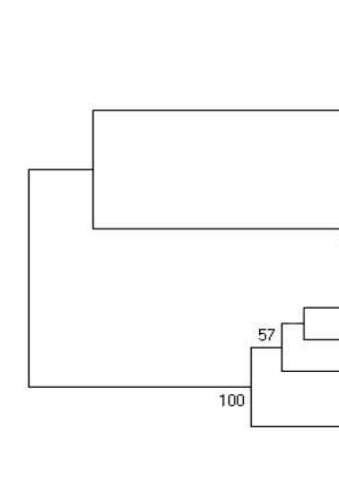

0.02
96 VNMN000500 Pinus dalatensis 68 VNMN000592 Pinus krempfii VNMN000586 Pinus latteri VNMN000439 Keteleeria evelyniana

VNMN000662 Dacrycarpus imbricatus - VNMN000670 Dacrydium elatum

VNMN000740 Nageia wallichiana

99 VNMN000810 Podocarpus neriifolius VNMN000325 Cophalotive manii VNMN000815 Amentopus

10.

- VNMN000434 Glyptostrobus pensilis

${ }_{99}\left[\begin{array}{l}- \text { VNMN000359 Fokienia hodginsii } \\ \text { VNMN000364 Calocedrus macrolepis }\end{array}\right.$

Pinaceae

Podocarpaceae

Cephalotaxaceae

Taxaceae Cupressaceae

Figure 3. (continued). 


\section{CONCLUSIONS}

Of the five gene regions, the highest level of nucleotide diversity was shown in the trn $\mathrm{H}$ $p s b \mathrm{~A}$ region (from 0.000 to $3.552 \%$ ), while the lowest was in the $r p o \mathrm{C} 1$ region (from 0.000 to $0.177 \%$ ). The matK gene is the most conservative (671 nucleotides) and the $t r n \mathrm{H}-p s b \mathrm{~A}$ gene region is the least (78 nucleotides). The capability to distinguish species among15 species of the matK region was the highest, with $100 \%$ discriminated species pairs. The ITS region did not have sufficient capability to distinguish 6 species pairs $(58.3 \%)$. Those results suggested that the three gene regions of $m a t \mathrm{~K}, t r n \mathrm{~L}$ and $r p o \mathrm{C} 1$ could be used as barcode for 15 conifer species in Central Highland of Vietnam.

Acknowledgments: This research was funded by Tay Nguyen 3 Program (Project code TN3/T15). The authors gratefully acknowledge the assistance and support in sample collection of Ngoc Linh Nature Reserve (Kon Tum province), Kon Ka Kinh National Park (Gia Lai province), Bidoup - Nui Ba National Park (Lam Dong province), Chu Yang Sin National Park (Dak Lak), Kon Tum Science and Technology Department, Dak Lak Science and Technology Department, and Lam Dong Science and Technology Department in Vietnam. We are grateful for Dr. Nguyen Tien Hiep for his help in the field survey and collection.

\section{REFFERENCES}

1. Nguyen Tien Hiep, Phan Ke Loc, Nguyen Duc To Luu, Philip Ian Thomas, Aljos Farjon, Leonid Averyanov and Jacinto Regalado Jr. - Viet Nam Conifers: Conservation Status Review 2004. Flora and Fauna International, Viet Nam Programme, Hanoi, 2005.

2. IUCN. 2013. IUCN Red List of Threatened Species (ver. 2013.1). Available at: http://www.iucnredlist.org. (Accessed: 12 June 2013).

3. Hebert P. D. N., Cywinska A., Ball S. L. and Waard J. R. - Biological identifications through DNA barcodes, Proc. R. Soc. Lond. B Biol. Sci. 270 (2003) 313-321.

4. Newmaster S. G., Fazekas A. J. and Ragupathy S. - DNA barcoding in land plants: evaluation of $r b c \mathrm{~L}$ in a multigene tiered approach, Can. J. Bot. 84 (2006) 335-341.

5. Lahaye R. M., Bank M. V. D. and Bogarin D. - DNA barcoding the floras of biodiversity hotspots, Proc. Nat. Acad. Sci. USA. 105 (2008) 2923-2928.

6. Cowan R. S., Chase M. W., Kress W. J. and Savolainen V. - 300,000 species to identify: problems, progress, and prospects in DNA barcoding of land plants, Taxon 55 (2006) 611-616.

7. Pennisi E. - Taxonomy. Wanted: a barcode for plants, Sci. 318 (2007) 190-191.

8. Little D. P., Knopf P. and Schulz C. - DNA Barcode Identification of Podocarpaceae The Second Largest Conifer Family, PLoS ONE 8 (11) (2013) e81008.

9. Bafeel S. O., Arif I. A., Bakir M. A., Khan H. A., Ahmad H., Farhan., Ali A., Homaidan A., Ahamed A. and Thomas J. - Comparative evaluation of PCR success with universal primers of maturase $\mathrm{K}(m a t \mathrm{~K})$ and ribulose-1, 5-bisphosphate carboxylase oxygenase large subunit $(r b c \mathrm{~L})$ for barcoding of some arid plants, POJ 4(4) (2011) 195-198.

10. Doyle J. J. and Doyle J. - A rapid DNA isolation procedure for small quantities of fresh leaf tissue, Phytochem. Bull. 19 (1987) 11-15. 
11. Tamura K., Dudley J., Nei M. and Kumar S. - MEGA4: Molecular Evolutionary Genetics Analysis (MEGA) software version 4.0, Mol. Biol. Evol. 24 (2007) 1596-1599.

12. Saitou N. and Nei M. - The neighbor-joining method: A new method for reconstructing phylogenetic trees, Mol. Biol. Evol. 4 (1987) 406-425.

13. Taberlet P., Coissac E., Pompanon F., Gielly L., Miguel C., Valentini A., Vermat T., Corthier G., Brochmann C. and Willerslev E. - Power and limitations of the chloroplast trnL (UAA) intron for plant DNA barcoding, Nucleic Acid Research 35 (2006) 14.

14. Liu Y., Yan H. F. and Ge X. J. - Evaluation of 10 plant barcordes in Bryophyta (Mosses), J. Syst. Evol. 48 (2010) 36-46.

15. Phong D. T., Tang D. V., Hien V. T. T., Ton N. D. and Hai N. V. - Nucleotide diversity of a nuclear and four chloroplast DNA regions in rare tropical wood species of Dalbergia in Vietnam: A DNA barcode identifying utility, Asian Journal of Applied Sciences 2 (2) 2014 116-125.

16. Song J., Yao H., Li Y., Li X., Lin Y., Liu C., Han J., Xie C. and Chen S. - Authentication of the family Polygonaceae in Chinese pharmacopoeia by DNA barcoding technique, J. Ethnop. 124 (2009) 434-439.

17. Hao D. C., Chen S. L. and Xiao P. G. - Sequence characteristics and divergent evolution of the chloroplast $p s b \mathrm{~A}-t r n \mathrm{H}$ noncoding region in gymnosperms, J. App. Genet. 51 (2010) 259-273.

18. Peter M. H., Laura L. F. and John L. S. - A DNA barcode for land plants, Proc. Natl. Acad. Sci. USA. 106 (2009) 12794-12797.

19. CBOL Plant Working Group - A DNA barcode for land plants, Proc. Natl. Acad. Sci. 106 (2009) 12794-12797.

20. Julian R. S., Robert F. C. N. and Btianna N. C. - Plant DNA barcodes and species resolution in sedges (Carex, Cyperaceae), Mol. Ecol. Res. 9 (2009) 151-163.

21. Fazekas A. J., Kuzmina L., Newmaster S. G. and Hollingsworth P. M. - DNA barcoding methords for land plants. In: Kress W. J., Erickson D. L. (ed) DNA barcodes: Methods and Protocols, Meth. Mol. Biol. 858 (2012) 223-252.

22. Sang T., Crawford D. J. and Stuessy T. F. - Chloroplast DNA phylogeny, reticulate evolution, and biogeography of Paeonia (Paeoniaceae), Am. J. Bot. 84 (8) (1997) 11201136.

23. Tate J. A. and Simpson B. B. - Paraphyly of Tarasa (Malvaceae) and diverse origins of the polyploidy species, Syst. Bot. 28 (2003) 723-737.

24. http://www.kew.org/barcoding/protocols.html. Accessed July 16, 2009. 